Article

\title{
Butyrate Conversion by Sulfate-Reducing and Methanogenic Communities from Anoxic Sediments of Aarhus Bay, Denmark
}

\author{
Derya Ozuolmez ${ }^{1}$, Elisha K. Moore ${ }^{2,3}$, Ellen C. Hopmans ${ }^{2}$, Jaap S. Sinninghe Damsté ${ }^{2,4}$ (i), \\ Alfons J. M. Stams ${ }^{1}$ and Caroline M. Plugge ${ }^{1, *(D)}$ \\ 1 Laboratory of Microbiology, Wageningen University \& Research, 6708 WE Wageningen, The Netherlands; \\ adaderya@gmail.com (D.O.); fons.stams@wur.nl (A.J.M.S.) \\ 2 Department of Marine Microbiology and Biogeochemistry, NIOZ Royal Netherlands Institute for Sea \\ Research, and Utrecht University, P.O. Box 59, 1790 AB Den Burg, The Netherlands; \\ mooreek@rowan.edu (E.K.M.); Ellen.Hopmans@nioz.nl (E.C.H.); jaap.damste@nioz.nl (J.S.S.D.) \\ 3 Department of Environmental Science, Rowan University, 201 Mullica Hill Rd, Glassboro, NJ 08028, USA \\ 4 Faculty of Geosciences, Utrecht University, P.O. Box 80.021, 3508 TA Utrecht, The Netherlands \\ * Correspondence: caroline.plugge@wur.nl; Tel.: +31-317-483116
}

Received: 27 March 2020; Accepted: 19 April 2020; Published: 22 April 2020

\begin{abstract}
The conventional perception that the zone of sulfate reduction and methanogenesis are separated in high- and low-sulfate-containing marine sediments has recently been changed by studies demonstrating their co-occurrence in sediments. The presence of methanogens was linked to the presence of substrates that are not used by sulfate reducers. In the current study, we hypothesized that both groups can co-exist, consuming common substrates $\left(\mathrm{H}_{2}\right.$ and/or acetate) in sediments. We enriched butyrate-degrading communities in sediment slurries originating from the sulfate, sulfate-methane transition, and methane zone of Aarhus Bay, Denmark. Sulfate was added at different concentrations $(0,3,20 \mathrm{mM})$, and the slurries were incubated at $10{ }^{\circ} \mathrm{C}$ and $25{ }^{\circ} \mathrm{C}$. During butyrate conversion, sulfate reduction and methanogenesis occurred simultaneously. The syntrophic butyrate degrader Syntrophomonas was enriched both in sulfate-amended and in sulfate-free slurries, indicating the occurrence of syntrophic conversions at both conditions. Archaeal community analysis revealed a dominance of Methanomicrobiaceae. The acetoclastic Methanosaetaceae reached high relative abundance in the absence of sulfate, while presence of acetoclastic Methanosarcinaceae was independent of the sulfate concentration, temperature, and the initial zone of the sediment. This study shows that there is no vertical separation of sulfate reducers, syntrophs, and methanogens in the sediment and that they all participate in the conversion of butyrate.
\end{abstract}

Keywords: marine sediment; sulfate-reducing bacteria; methanogenic archaea; syntrophy; intact polar lipids; Aarhus Bay

\section{Introduction}

Coastal marine ecosystems receive a regular input of organic matter from primary production of plankton, macroalgae, and vascular plants and the influx of rivers, and they are important in the remineralization of organic matter [1,2]. Most particulate organic matter is rapidly deposited on the coastal shelf. High microbial activity in the sediment layers leads to the formation of distinct biogeochemical zones. The depth range of each zone varies strongly depending on chemical changes in the sediment pore water, the rates of sediment accumulation, and replenishment of electron acceptors from overlying seawater [3]. In coastal marine sediments, the thickness of the oxic surface layer can be just a few millimeters [2]. Where oxygen is depleted, the sediment becomes anoxic. In the anoxic part 
of the sediment, nitrate, manganese, iron, sulfate, and carbon dioxide, in an order of decreasing energy gain, serve as terminal electron acceptors for the mineralization processes $[4,5]$.

Anaerobic degradation of organic matter in marine sediments is a complex sequential process in which a variety of physiologically different microorganisms take part [1]. The first step is an extracellular hydrolysis of polymers (polysaccharides, proteins, nucleic acids, and lipids). Primary fermentative bacteria ferment the monomers and oligomers to fatty acids, alcohols, aromatic acids, $\mathrm{H}_{2}$, and $\mathrm{CO}_{2}$. Some of these fermentation products, such as acetate, $\mathrm{H}_{2}, \mathrm{CO}_{2}$, and other one-carbon compounds, can be converted directly to methane and carbon dioxide by methanogens. In methanogenic environments, secondary fermenters or proton reducers convert alcohols, aliphatic and aromatic fatty acids to acetate, formate, $\mathrm{H}_{2}$, and $\mathrm{CO}_{2}$, which are subsequently used by the methanogens [6]. In this way, a syntrophic relationship is established between microorganisms that convert organic compounds and methanogens (Table S1) [6]. The conversion of polymers in sulfate-rich anoxic habitats such as marine sediments is different. In contrast to methanogens, sulfate-reducing bacteria can metabolize all products of primary fermentation and oxidize them to carbon dioxide, while reducing sulfate to sulfide [7].

Sulfate reduction and methanogenesis have been reported to occur simultaneously in anoxic marine environments where input of organic carbon is high $[3,8,9]$. In such environments, the use of noncompetitive methylated substrates by [10] methanogens was first suggested to enable cohabitation of both functional microbial groups. However, several studies demonstrated the consumption of common substrates, $\mathrm{H}_{2}$ and acetate, by both microbial groups in sulfate-rich sediments [11]. Sulfate-reducing bacteria (SRB) were detected in the methane zone in comparable numbers as in the sulfate zone of sediments of the Black Sea and Aarhus Bay [12,13]. The niche differentiation of the two groups of microbes is not fully understood. Thus far, syntrophic conversion of fatty acids in marine environments has received little attention. In [14], marine butyrate-degrading syntrophs in the sulfate zone were detected and it was suggested that syntrophic interactions constitute a significant methane source in marine sediments. As high methane concentrations were observed under conditions with high sulfate concentrations in a hydrocarbon-contaminated aquifer, it was concluded that butyrate was metabolized mainly syntrophically [15]. Other studies reported the existence of butyrate-degrading syntrophic genera Syntrophus and Syntrophomonas in different sulfate-containing environments [16-18].

As both Syntrophus and Syntrophomonas cannot reduce sulfate, and known butyrate-degrading SRB are not able to grow syntrophically [19], it is not clear if butyrate-degrading SRB can perform a syntrophic lifestyle to enable them to thrive in high- and low-sulfate environments. Thus, it is important to understand how sulfate reducers and syntrophs interact with methanogens in the presence and absence of sulfate.

In this study, we investigated butyrate-degrading communities from the sulfate, sulfate-methane transition, and methane zone in anoxic sediments of Aarhus Bay, Denmark. We set up batch slurry incubations and applied different sulfate concentrations $(0,3,20 \mathrm{mM})$ to see which butyrate-utilizing sulfate reducers and syntrophs become dominant in response to sulfate availability and which methanogens contribute to butyrate conversion in the presence or absence of sulfate.

\section{Materials and Methods}

\subsection{Sediment Sampling}

Sediment was collected at station M1 located in the central part of the Aarhus Bay, Denmark $\left(56^{\circ} 07^{\prime} 066^{\prime \prime} \mathrm{N}, 10^{\circ} 20^{\prime} 793^{\prime \prime} \mathrm{E}\right)$ at a water depth of $15 \mathrm{~m}$ during a research cruise with RV Tyra in May 2011. The in situ temperature of the sediment was $\sim 9^{\circ} \mathrm{C}$. Two $3 \mathrm{~m}$-long gravity cores were retrieved; one of them was sectioned in $10 \mathrm{~cm}$ depth intervals for physical, chemical, and molecular analyses and the other one was kept intact in the core liners, in sealed gas-tight plastic bags containing AnaeroGen sachets (Oxoid, Landsmeer, Netherlands) at $4{ }^{\circ} \mathrm{C}$ until further processing. 


\subsection{Sediment Pore Water Analysis}

Methane, sulfate, and sulfide analysis from sediment pore water was performed on the sampling day at the laboratories of Center for Geomicrobiology, Aarhus University, Denmark. The pore water concentrations of sulfate and methane were determined as described by [20]. Hydrogen sulfide was quantified in zinc-preserved pore water samples by the methylene blue method [21].

\subsection{Sediment Slurry Incubations}

Sediments from three different biogeochemical zones were used to establish replicate sediment slurries. Stored sediment cores were processed under aseptic and anaerobic conditions in the laboratory. Subsamples were mixed in an anaerobic chamber and used as inoculum for sediment slurry enrichments. An amount of $100 \mathrm{~mL}$ of the homogenized sediment from each zone was mixed with $300 \mathrm{~mL}$ of anaerobic mineral salts medium in $1 \mathrm{~L}$ serum bottles. The medium composition was as follows $(\mathrm{g} / \mathrm{L})$ : $\mathrm{KH}_{2} \mathrm{PO}_{4}(0.41), \mathrm{Na}_{2} \mathrm{HPO}_{4} \cdot 2 \mathrm{H}_{2} \mathrm{O}(0.53), \mathrm{NH}_{4} \mathrm{Cl}(0.3), \mathrm{CaCl}_{2} \cdot 2 \mathrm{H}_{2} \mathrm{O}(0.11), \mathrm{MgCl}_{2} \cdot 6 \mathrm{H}_{2} \mathrm{O}$ (3), $\mathrm{NaHCO}_{3}$ (4), $\mathrm{Na}_{2} \mathrm{~S} \cdot 9 \mathrm{H}_{2} \mathrm{O}(0.024), \mathrm{KCL}(0.5), \mathrm{NaCl}$ (25). The medium was supplemented with $1 \mathrm{~mL} / \mathrm{L}$ of acid trace element solution ( $50 \mathrm{mM} \mathrm{HCl}, 1 \mathrm{mM} \mathrm{H}_{3} \mathrm{BO}_{3}, 0.5 \mathrm{mM} \mathrm{MnCl}_{2}, 7.5 \mathrm{mM} \mathrm{FeCl}_{2}, 0.5 \mathrm{mM} \mathrm{CoCl}_{2}, 0.1 \mathrm{mM}$ $\left.\mathrm{NiCl}_{2}, 0.5 \mathrm{mM} \mathrm{ZnCl}_{2}\right), 1 \mathrm{~mL} / \mathrm{L}$ of alkaline trace element solution $\left(10 \mathrm{mM} \mathrm{NaOH}, 0.1 \mathrm{mM} \mathrm{Na} 2 \mathrm{SeO}_{3}\right.$, $0.1 \mathrm{mM} \mathrm{Na}_{2} \mathrm{WO}_{4}, 0.1 \mathrm{mM} \mathrm{Na}_{2} \mathrm{MoO}_{4}$ ), and $10 \mathrm{~mL} / \mathrm{L}$ vitamin solution (Biotin $20 \mathrm{mg} / \mathrm{L}$, Nicotinamid 200 mg/L, p-Aminobenzoic acid 100 mg/L, Thiamin 200 mg/L, Pantothenic acid 100 mg/L, Pyridoxamine $500 \mathrm{mg} / \mathrm{L}$, Cyanocobalamine $100 \mathrm{mg} / \mathrm{L}$, Riboflavin $100 \mathrm{mg} / \mathrm{L}$ ). Bottles were closed with butyl rubber stoppers, and the headspace was exchanged with $\mathrm{N}_{2} / \mathrm{CO}_{2}(80: 20 \%, v / v)$, and the final pressure was adjusted to $1.5 \mathrm{kPa}$. An amount of $10 \mathrm{mM} \mathrm{Na-butyrate} \mathrm{was} \mathrm{used} \mathrm{as} \mathrm{carbon} \mathrm{source} \mathrm{with} \mathrm{and} \mathrm{without}$ $20 \mathrm{mM}$ sulfate in sulfate zone and methane zone slurries, and with $3 \mathrm{mM}$ and $20 \mathrm{mM}$ sulfate for sulfate-methane transition zone slurries. Control bottles were prepared in the same manner, without addition of butyrate. One set of the bottles representing each condition in duplicate was incubated at $10{ }^{\circ} \mathrm{C}$ to mimic in situ sediment temperature [22], and the other set was kept at $25^{\circ} \mathrm{C}$ statically throughout the experiment. Regular liquid and gas sampling was performed to monitor substrate consumption, product formation, and to carry out molecular analysis. Regular additions of butyrate and/or sulfate were done as soon as they were depleted to maintain the slurry conditions.

\subsection{Analytical Methods}

$\mathrm{CH}_{4}$ in the headspace of slurries was analyzed by gas chromatography as described previously [23]. Volatile fatty acids from centrifuged $(10,000 \times g, 10 \mathrm{~min})$ samples of the sediment slurries were analyzed by HPLC as described previously [23]. Data analyses were performed using ChromQuest (Thermo Scientific, Waltham, MA, USA) and Chromeleon software (Thermo Scientific, Waltham, MA). Sulfate and sulfide were quantified as described in [24].

\subsection{DNA Extraction}

Genomic DNA was extracted from the sediment and enrichment slurry samples using the FastDNA SPIN Kit for Soil (MP Biomedicals, Solon, OH, USA) according to manufacturer's protocol, with the following adaptations to increase the DNA yield. Sediment or slurry sample $(5 \mathrm{~mL})$ was suspended in $10 \mathrm{~mL}$ of phosphate-buffered saline (PBS), sonicated at low power to detach cells from the solid phase, and was centrifuged at $4700 \times g$ for $20 \mathrm{~min}$. The supernatant was discarded and remaining pellet was re-suspended in $10 \mathrm{~mL} 0.5 \mathrm{M}$ EDTA, $\mathrm{pH}$ 8, and incubated overnight at $4{ }^{\circ} \mathrm{C}$ to dissolve humic substances. After incubation, the suspension was centrifuged at $4700 \times g$ for $10 \mathrm{~min}$, washed with PBS, and DNA was extracted from the pellet. The DNA was quantified with a Nanodrop ND-1000 spectrophotometer (Nanodrop Technologies, Wilmington, DE, USA). 


\section{6. $16 \mathrm{~S}$ rRNA Gene Amplicon Pyrosequencing}

Bacterial 16S rRNA gene fragments were amplified using barcoded primers covering the V1-V2 region of the bacterial 16S rRNA gene. The forward primer consisted of the 27F-DegS primer (5'-GTTYGATYMTGGCTCAG-3') appended with the titanium sequencing adaptor A (5'-CCAT CTCATCCCTGCGTGTCTCCGACTCAG-3') and an eight nucleotide sample specific barcode at the $5^{\prime}$ end. An equimolar mix of two reverse primers was used, i.e., 338RI (5'-GCWGCCTCCCGTA GGAGT-3') and 338RII (5'-GCWGCCACCCGTAGG TGT-3') that carried the titanium adaptor B (5'-CCTATCCCCTGTGTGCCTTGGCAG TCTCAG-3') at the $5^{\prime}$ end. Sequences of both titanium adaptors were purchased from GATC Biotech (Konstanz, Germany). Genomic DNA was diluted to a concentration of $20 \mathrm{ng} / \mu \mathrm{L}$ based on Qubit ${ }^{\circledR} 2.0$ fluorometer readings, and amplicons were generated as described in [25]. Amplicons were sequenced using a 454 FLX genome sequencer in combination with titanium chemistry (GATC Biotech AG, Konstanz, Germany. The demultiplexed reads of the 16S rRNA gene amplicon sequences of Bacteria were deposited at the European Nucleotide Archive (ENA) under study PRJEB36640.

\subsection{Analysis and Interpretation of the Pyrosequencing Data}

Pyrosequencing data was analyzed as described in [24]. The relative amount of reads of every operational taxonomic unit (OTU) to the total amount of reads per sample was quantified, and the average relative amount of reads per representative OTU of each slurry sample was calculated.

\subsection{Illumina HiSeq Analysis of Archaeal Community}

Extracted DNA from the samples taken on the last incubation day from all slurries was used for archaeal community analysis. Barcoded amplicons were generated using a two-step PCR method that was shown to reduce the impact of barcoded primers on the outcome of microbial profiling [26]. Amplification was done as described by [27].

16S rRNA gene sequencing data was analyzed using NG-Tax, an in-house pipeline [28]. Paired-end libraries were filtered to contain only read pairs with perfectly matching barcodes, and those barcodes were used to demultiplex reads by sample. Operational taxonomic units (OTUs) were defined using an open reference approach, and taxonomy was assigned to those OTUs using the SILVA 16S rRNA gene reference database [29]. Microbial composition plots were generated using a workflow based on Quantitative Insights Into Microbial Ecology (QIIME) v1.2 [30]. The demultiplexed reads of the $16 \mathrm{~S}$ rRNA gene amplicon sequences of the Archaea were deposited at the European Nucleotide Archive (ENA) under study PRJEB36882.

\subsection{Intact Polar Lipid (IPL) Extraction and HPLC-ESI/IT/MS Analysis}

The slurry samples which were used for molecular analysis were also used for lipid analysis. Additionally, methane zone slurry samples which were not analyzed for molecular analysis were extracted and analyzed in order to confirm the presence or absence of trimethylornithine lipids (TMOs). IPLs were extracted from $\sim 0.1 \mathrm{~g}$ freeze-dried powdered samples using a modified Bligh and Dyer method [31-33]. The extracts were dried under a flow of $\mathrm{N}_{2}$ and stored at $-20{ }^{\circ} \mathrm{C}$ until analysis. The dried extract residue was dissolved in hexane/2-propanol/ $\mathrm{H}_{2} \mathrm{O}(718: 271: 10, v / v / v)$ injection solvent, filtered through a $0.45 \mu \mathrm{m}, 4 \mathrm{~mm}$ diameter True ${ }^{\mathrm{TM}}$ Regenerated Cellulose syringe filter (Grace Davison) prior to injection and analysis. Extracted IPLs from the enrichment slurries were analyzed by high-performance liquid chromatography-electrospray ionization-ion trap mass spectrometry (HPLC-ESI/IT/MS) according to [34], with some modifications [35]. IPL abundance was assessed by integrating the HPLC-ESI/IT/MS mass chromatogram for each individual identified IPL, and areas were summed per IPL head group and reported per gram of slurry, dry weight. 


\subsection{Statistical Analysis}

Redundancy analysis was performed as implemented in the CANOCO 5 software package (Biometris, Wageningen, The Netherlands) in order to assess to what extent experimental variables influenced the microbial community composition. The experimental variables tested were the incubation temperature, total concentrations of sulfate, butyrate, acetate, and methane consumed/produced by the end of the incubations. A Monte Carlo permutation test based on 499 random permutations was used to determine which of the experimental variables significantly contributed to the observed variance in the composition of microbial communities at the order (for bacteria) and family level (for archaea). Orders and families of at least $5 \%$ relative abundance in any sample were included in the analysis. The community structure was visualized via ordination triplots with scaling focused on intersample differences. Correlations between bacterial and archaeal groups and experimental parameters were determined by means of the two-tailed Spearman's rank-order correlation test using the statistical software SPSS Statistics (IBM SPSS Statistics, Version 22, IBM Corp., Armonk, NY, USA). A statistical significance level of 5\% was applied. Multivariate canonical correspondence analysis (CCA) [36] was performed using $\mathrm{R}$ statistical analysis software to find phylogenetic groups and IPLs that correlate with each other or with particular incubation conditions.

\section{Results}

\subsection{Sampling Site Geochemistry}

Zones were defined based on sulfate and methane concentrations determined using pore water extracted from sediment during the sampling cruise. The sulfate concentration decreased from $18.5 \mathrm{mM}$ at $15 \mathrm{~cm}$ of the core to a low background value at $170 \mathrm{~cm}$. Methane increased steeply with depth below $120 \mathrm{~cm}$ and reached a plateau of $2 \mathrm{mM}$ at $225 \mathrm{~cm}$. The sediment core was divided into three pieces representing the sulfate zone (SZ) $(15-120 \mathrm{~cm})$, the sulfate-methane transition zone (SMTZ) $(120-170 \mathrm{~cm})$, and the methane zone (MZ) $(170-300 \mathrm{~cm})$ (Figure S1).

\subsection{Slurry Incubations}

\subsubsection{Sulfate Zone Sediment Slurries}

Slurries with sediment from the sulfate zone were incubated for 514 days at $25{ }^{\circ} \mathrm{C}$ and $10{ }^{\circ} \mathrm{C}$ (Figure 1). Total amounts of the butyrate and sulfate consumed and acetate, sulfide, and methane produced in all slurries are listed in Table S2. Conversion of butyrate in sulfidogenic slurries started after 12 days of incubation (Figure 1A,B). Repeated additions of butyrate and sulfate caused a steady increase in acetate and sulfide. Methane formation was observed after 309 days at $25^{\circ} \mathrm{C}$ and after 260 days at $10^{\circ} \mathrm{C}$, and methane increased with time (Figure $1 \mathrm{~A}, \mathrm{~B}$ ).

In the methanogenic slurries, where no additional sulfate was added, about $1 \mathrm{mM}$ sulfate was measured at the start of the incubation, which presumably originated from the sediment (Figure 1C,D). In the first 40 days of incubation at $25^{\circ} \mathrm{C}$, butyrate conversion coupled to sulfate reduction occurred. Methane formation started on day 50, after sulfate had been depleted. Repeated additions of butyrate yielded high methane and acetate accumulation. Acetate was gradually consumed after day 203 at $25{ }^{\circ} \mathrm{C}$ (Figure 1C). Butyrate conversion in the $10{ }^{\circ} \mathrm{C}$ slurry was rather slow (Figure 1D). Trace amounts of sulfate that originated from the sediment depleted within 70 days, and methane formation started on day 122 . The methane concentration in the $10^{\circ} \mathrm{C}$ slurry at the end of the incubation period was three times lower than in the $25^{\circ} \mathrm{C}$ slurry. 

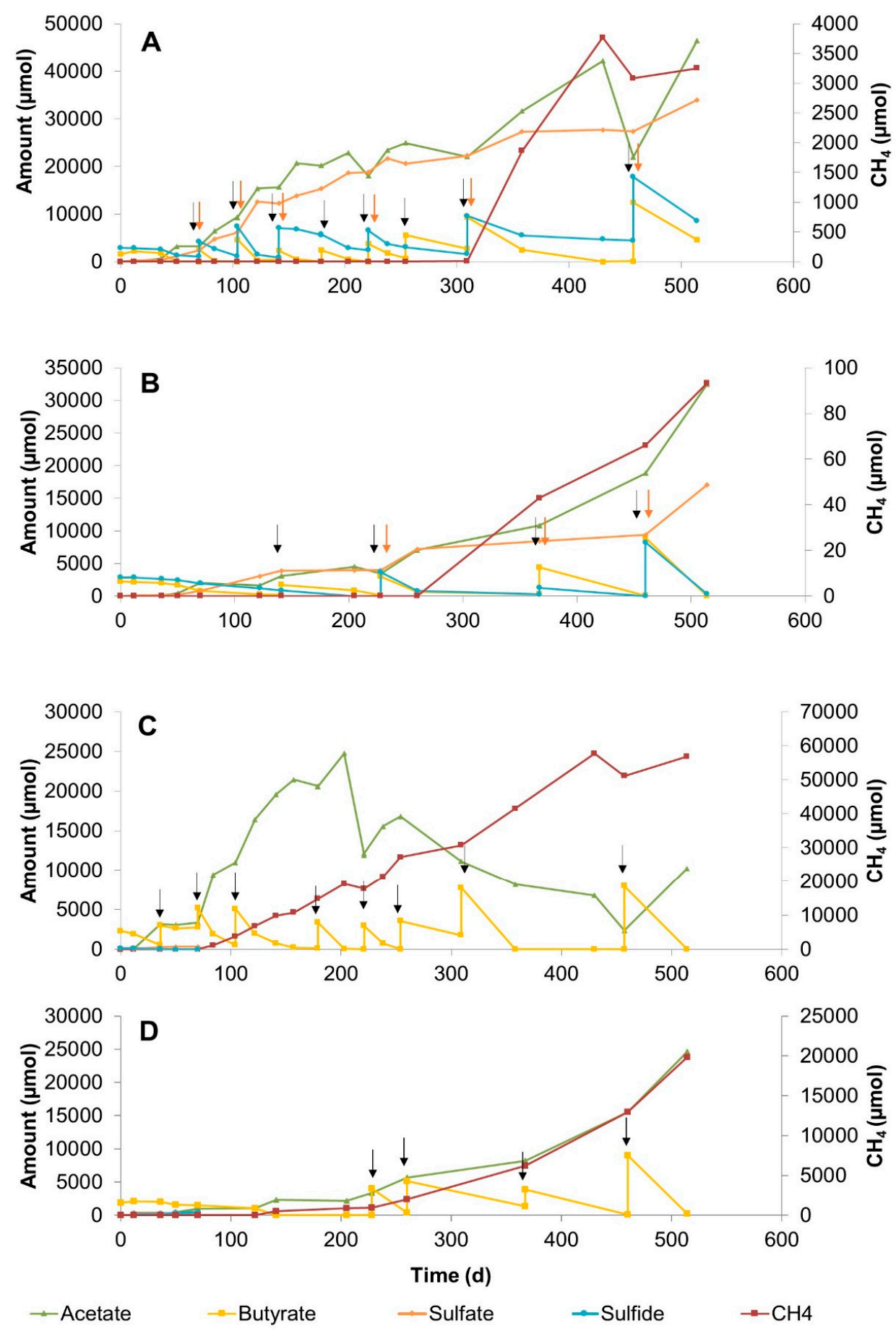

Figure 1. Changes in butyrate, sulfate, acetate, sulfide, and methane concentrations during 514 days of incubation in sediment slurry enrichments constituted of sulfate zone sediment. (A) Slurry SZB4, with $20 \mathrm{mM}$ sulfate addition at $25^{\circ} \mathrm{C}$, (B) Slurry SZB7, with $20 \mathrm{mM}$ sulfate addition at $10^{\circ} \mathrm{C}$, (C) Slurry SZB1, without sulfate addition at $25^{\circ} \mathrm{C}$, (D) Slurry SZB5, without sulfate addition at $10^{\circ} \mathrm{C}$. Arrows denote the time points for the additions of sulfate (red) and butyrate (black).

\subsubsection{Sulfate-Methane Transition Zone Sediment Slurries}

Slurries of SMTZ sediments with low $(3 \mathrm{mM})$ and high $(20 \mathrm{mM})$ sulfate were incubated for 571 days at $25^{\circ} \mathrm{C}$ and $10^{\circ} \mathrm{C}$ (Figure 2). Butyrate conversion in high-sulfate slurries coupled to sulfate reduction at both temperatures (Figure 2A,B). Acetate and sulfide concentrations increased by repeated 
butyrate and sulfate feeds. Methane production started on day 120 at $25^{\circ} \mathrm{C}$ (Figure 2A) and on day 229 at $10^{\circ} \mathrm{C}$ (Figure $2 \mathrm{~B}$ ), and increased slowly. The amount of methane ranged between 8 and $48 \mu$ mole at both temperatures until 500 days. However, it reached to around $4200 \mu$ mole at day 571 in slurry at $25{ }^{\circ} \mathrm{C}$.

In the low-sulfate slurries, the total amount of butyrate converted in the $25^{\circ} \mathrm{C}$ slurry was slightly higher than in the $10^{\circ} \mathrm{C}$ slurry (Figure $2 \mathrm{C}, \mathrm{D}$ ). Twice as much methane concentration was measured in the $25{ }^{\circ} \mathrm{C}$ slurry by the end of incubation as compared with the $10{ }^{\circ} \mathrm{C}$ slurry. Acetate accumulated in the $10^{\circ} \mathrm{C}$ slurry (Figure 2D), whereas it was initially formed and consumed after 300 days of incubation in the $25^{\circ} \mathrm{C}$ slurry (Figure 2C).

\subsubsection{Methane Zone Sediment Slurries}

Methane zone sediment slurries were incubated for 570 days at $25^{\circ} \mathrm{C}$ and $10{ }^{\circ} \mathrm{C}$ with and without the addition of sulfate $(20 \mathrm{mM})$ (Figure 3). In the $25^{\circ} \mathrm{C}$ slurries, conversion of butyrate started directly (Figure 3A,C). Repeated additions of butyrate and/or sulfate led to a steady increase in acetate and sulfide concentrations. Methane formation in the sulfidogenic slurry was observed after 90 days at $25^{\circ} \mathrm{C}$ (Figure $3 \mathrm{~A}$ ), and methane concentration increased with time, whereas no methane was detected at $10^{\circ} \mathrm{C}$ (Figure $3 \mathrm{~B}$ ) during the whole incubation period.

Sulfate reduction and methanogenesis co-occurred in the sulfidogenic slurry incubated at $25^{\circ} \mathrm{C}$ (Figure 3A). The fastest butyrate conversion was observed in the methanogenic slurry at $25^{\circ} \mathrm{C}$ (Figure 3C). Trace amounts of sulfate detected in the slurry at the beginning of incubation were reduced during butyrate conversion within the first 40 days. Methane was detected at day 64 and increased rapidly due to fast conversion of butyrate. Hence, acetate and methane amounts increased steeply within 200 days. A steady acetate consumption occurred after day 214. Even though acetate was produced after butyrate feeds, acetate was consumed again almost completely after 500 days of incubation. Since the methane pressure in these bottles was very high, at day 277, excess headspace gas had to be exhausted (Figure 3C). Butyrate conversion in the methanogenic slurry at $10^{\circ} \mathrm{C}$ proceeded much slower (Figure 3D). Methane production started at day 200, and methane concentrations increased gradually. In total, 11 times less methane was produced in the methanogenic slurry incubated at $10^{\circ} \mathrm{C}$ compared with the one incubated at $25^{\circ} \mathrm{C}$ within 570 days.

\subsection{Bacterial and Archaeal Community Composition}

The long-term incubation of the sediment slurries with butyrate in the presence and absence of sulfate resulted in the development of different microbial communities at the end of incubation. PCR-amplified partial 16S rRNA gene fragments obtained from the last sampling time of all slurries were sequenced. After filtering and trimming, between 3202 and 18,687 high-quality sequences were detected per sample (Table S3), and these clustered in 62-133 operational taxonomic units (OTUs) per sample. OTUs were classified into 33 phyla, with $96 \%$ of the OTUs belonging to 6 phyla, namely, Proteobacteria (45.9\%), Chloroflexi (23.6\%), Firmicutes (17.7\%), Bacteroidetes $(5.3 \%)$, Spirochaetes $(2.7 \%)$, and Candidate division OP9 (1.1\%). Different phylotypes were abundant in libraries from the different zones. In sulfate and methane zone sediment libraries, sequences belonging to Gammaproteobacteria ( $64 \%$ and $54 \%$, respectively) were dominant, whereas in the SMTZ sediment libraries, sequences related to Desulfobacteraceae (79\%) belonging to the class Deltaproteobacteria were highly detected (Figure S2). Within the Proteobacteria phylum, Desulfobacteraceae was the main family, containing $61 \%$ of the reads. A similar dominance of the Anaerolineaceae family with $89.2 \%$ reads was observed in the Chloroflexi phylum. In the Firmicutes phylum, the Syntrophomonadaceae family covered $39.9 \%$ of the reads, while $50.9 \%$ of the reads belonged to uncultured Firmicutes. All slurries were dominated by Desulfobacteraceae, Anaerolineaceae, Syntrophomonadaceae, and uncultured Clostridiales. Anaerolineales was observed to be negatively correlated to the other two dominant orders, Desulfobacterales and Clostridiales, but positively correlated to all environmental parameters, with a strong correlation to temperature $(p<0.01)$, butyrate $(p<0.01)$, and acetate $(p<0.05)$ (Figure 4B and Figure S3). The relative abundance of Desulfobacterales 
(OTU 27) was associated with sulfate concentration and independent of the temperature (Figure 4B and Figure S3). Despite the overall dominance of these families, the relative abundances of each family varied in the different slurry samples. The most abundant OTUs belonged to Desulfobacterium in the phyla Proteobacteria, uncultured Anaerolineaceae in the phylum Chloroflexi, Syntrophomonas in the phyla Firmicutes, uncultured Desulfobacteraceae in the phyla Proteobacteria, and uncultured Clostridiales in the phylum Firmicutes (Figure 4A).
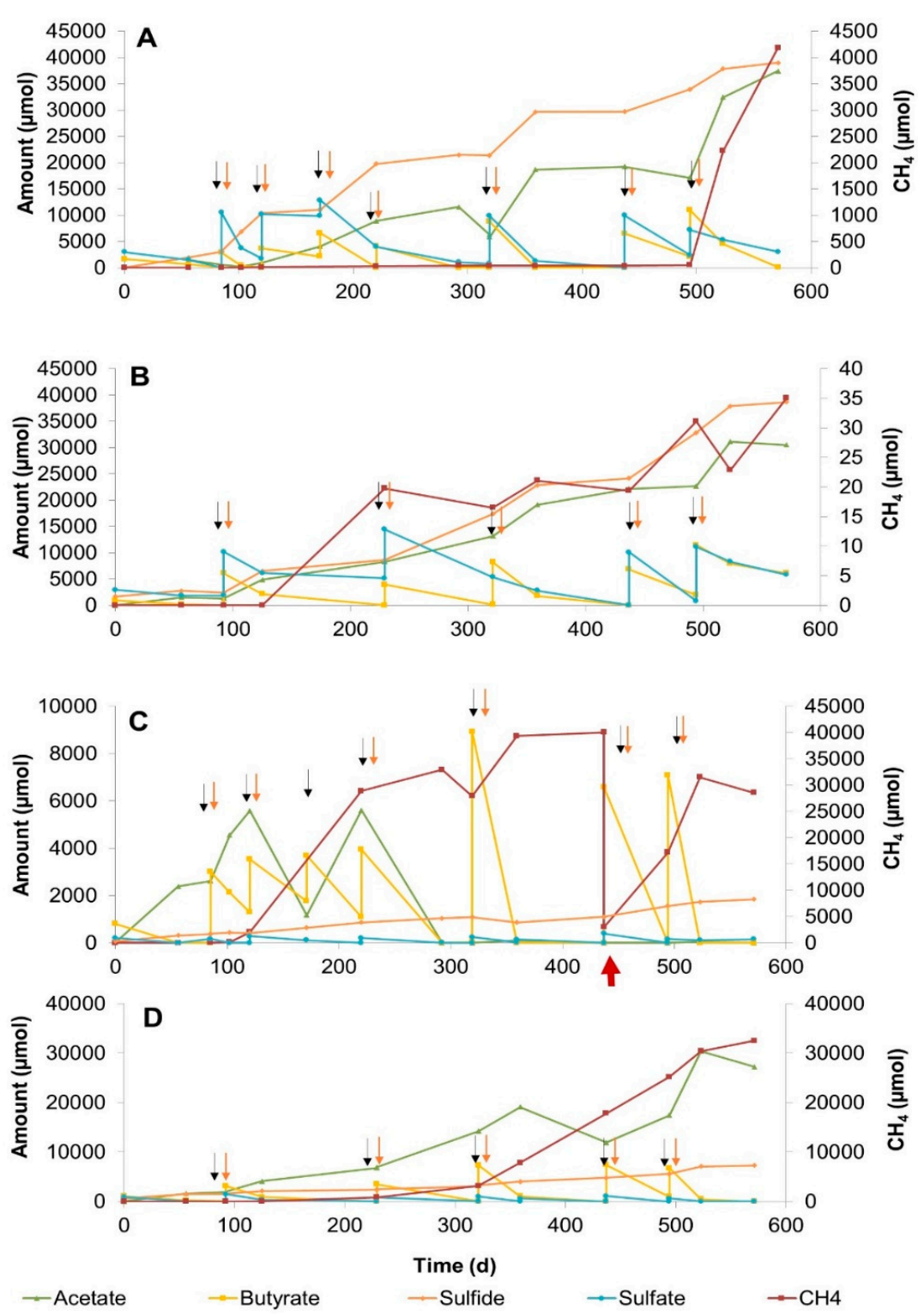

Figure 2. Changes in butyrate, sulfate, acetate, sulfide, and methane concentrations during 571 days of incubation in sediment slurry enrichments constituted of sulfate-methane transition zone sediment. (A) Slurry SMTZB3, with $20 \mathrm{mM}$ sulfate addition at $25^{\circ} \mathrm{C}$, (B) Slurry SMTZB7, with $20 \mathrm{mM}$ sulfate addition at $10{ }^{\circ} \mathrm{C}$, (C) Slurry SMTZB1, with $3 \mathrm{mM}$ sulfate addition at $25^{\circ} \mathrm{C}$, (D) Slurry SMTZB6, with $3 \mathrm{mM}$ sulfate addition at $10^{\circ} \mathrm{C}$. Arrows denote the time points for the additions of sulfate (red) and butyrate (black). The red arrow in Figure $2 \mathrm{C}$ indicates the time point that the excess amount of gas was exhausted from the headspace. 

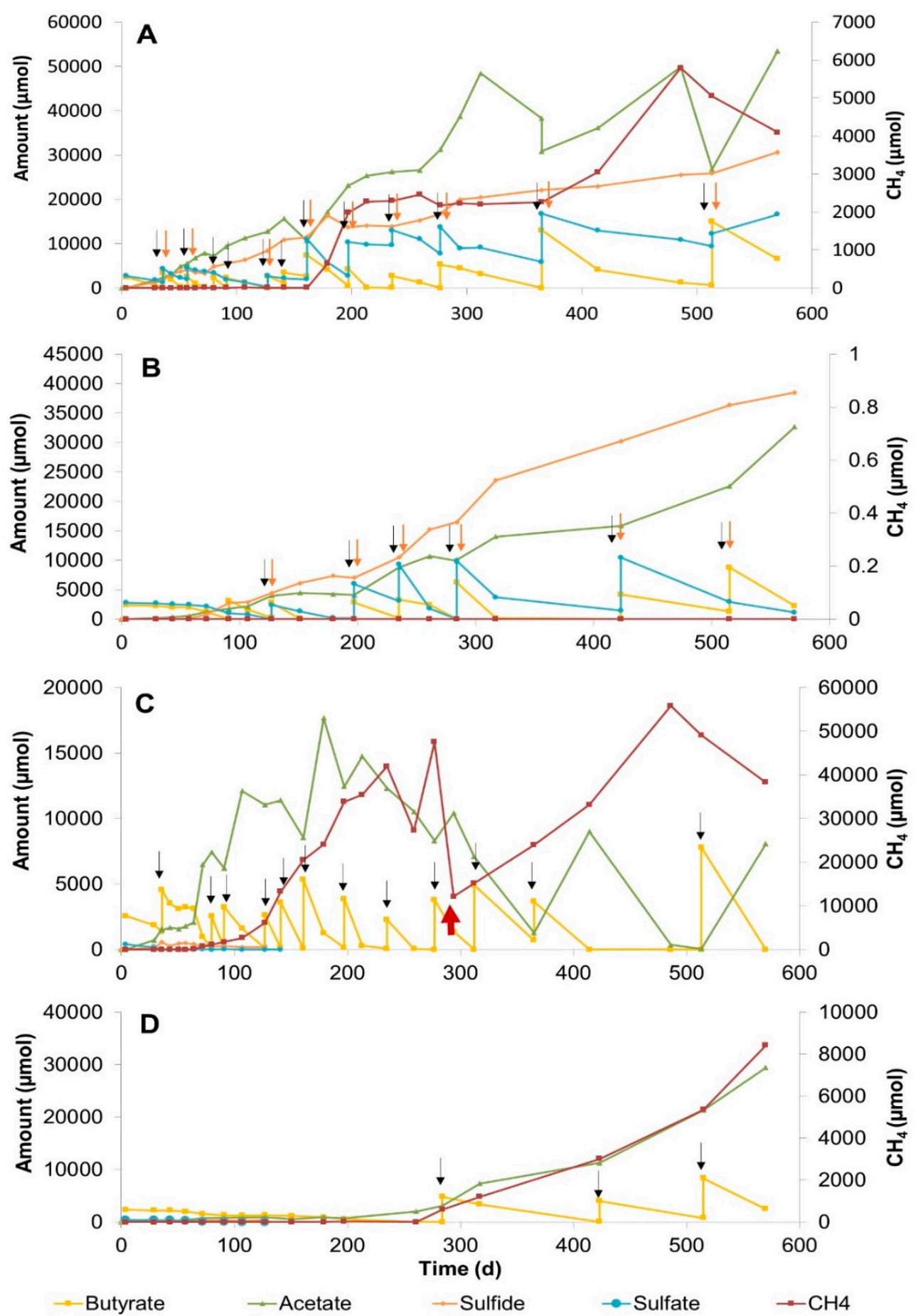

Figure 3. Changes in butyrate, sulfate, acetate, sulfide, and methane concentrations during 570 days of incubation in sediment slurry enrichments constituted of methane zone sediment. (A) Slurry MZB3, with $20 \mathrm{mM}$ sulfate addition at $25{ }^{\circ} \mathrm{C}$, (B) Slurry MZB2, with $20 \mathrm{mM}$ sulfate addition at $10{ }^{\circ} \mathrm{C},(\mathbf{C})$ Slurry MZB5, without sulfate addition at $25^{\circ} \mathrm{C}$. (D) Slurry MZB8, without sulfate addition at $10{ }^{\circ} \mathrm{C}$. Arrows denote the time points for the additions of sulfate (red) and butyrate (black). The red arrow in Figure $3 \mathrm{C}$ indicates the time point that the excess amount of gas was exhausted from the headspace. 


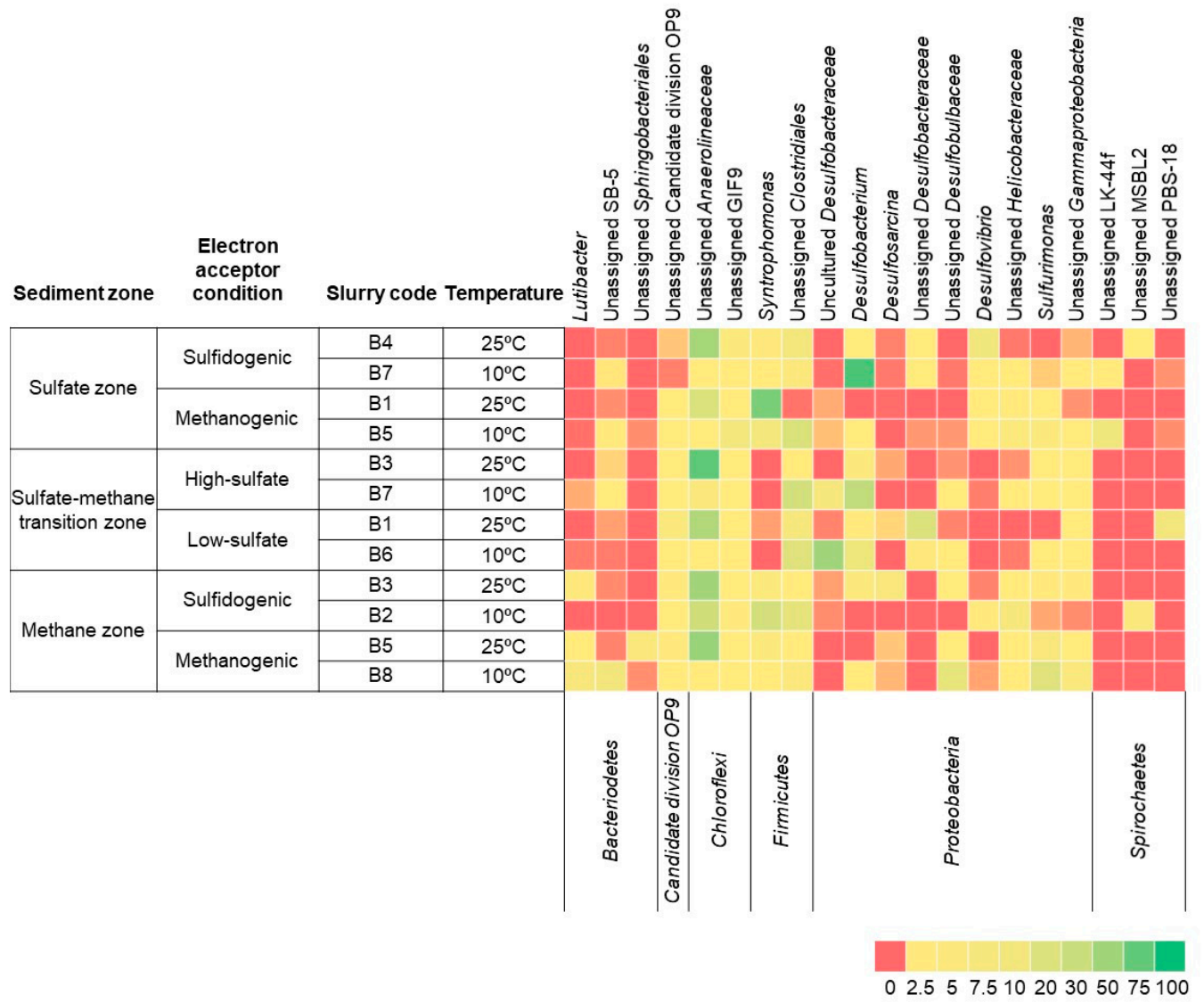

A

Figure 4. Cont. 


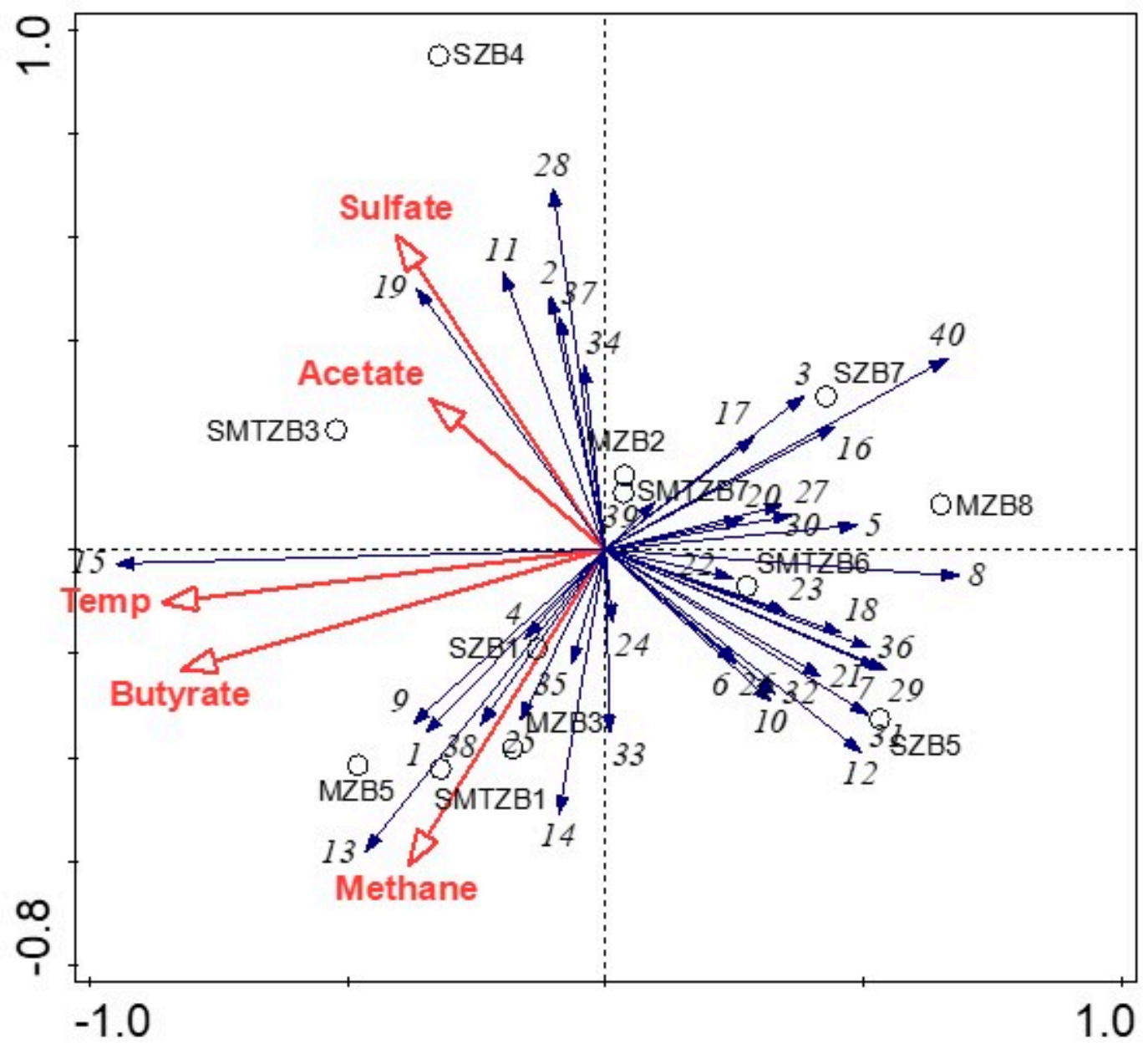

B

Figure 4. (A) The heatmap depicts the relative percentage of the most common ( $>5 \%$ ) bacterial $16 \mathrm{~S}$ rRNA gene sequences across the 12 slurries analyzed. The heatmap colors represent the relative percentage of the bacterial assignments within each sample. Colors shifted towards dark green indicate higher abundance. Taxonomy is shown at the genus level (unless unassigned) above and at the phylum level below the heatmap. (B) Redundancy Analysis Triplot showing relationship between bacterial community composition at order level and environmental parameters. Environmental variables are given as red vectors. Blue vectors represent bacterial orders. Orders were included with a relative abundance of at least $1 \%$ in any sample. Vector length gives the variance that can be explained by a particular environmental parameter. Perpendicular distance reflects association, with smaller distances indicating a larger association. Temp: Temperature.

OTU numbers and corresponding taxa are as follows: (1) Bacteria-Other, (2) ActinobacteriaOPB41, (3) Bacteroidetes-BD2-2, (4) Bacteroidetes-Bacteroidales, (5) Bacteroidetes-Cytophagales, (6) Bacteroidetes- Flavobacteriales, (7) Bacteroidetes-SB-1-uncultured, (8) Bacteroidetes-B-5-other, (9) Bacteroidetes-Sphingobacteriales, (10) Bacteroidetes-VC2.1.Bac22, (11) Bacteroidetes-vadinHA17other, (12) Bacteroidetes-vadinHA17-uncultured bacterium, (13) Candidate division OP9-uncultured bacterium, (14) Chloroflexi-Anaerolineae-other, (15) Chloroflexi-Anaerolineales, (16) ChloroflexiGIF9-uncultured bacterium, (17) Chloroflexi-MSBL5-uncultured bacterium, (18) ChloroflexivadinBA26-uncultured bacterium, (19) Cyanobacteria-Chloroplast-uncultured bacterium, (20) Deferribacteres-LCP-89, (21) Elusimicrobia-Lineage_IV-uncultured bacterium, (22) FirmicutesClostridiales, (23) Nitrospirae-Nitrospirales, (24) Proteobacteria-Burkholderiales, (25) Proteobacteria- 
Hydrogenophilales, (26) Proteobacteria-Desulfarculales, (27) Proteobacteria-Desulfobacterales, (28) Proteobacteria- Desulfovibrionales, (29) Proteobacteria-Desulfuromonadales, (30) ProteobacteriaSva0485, (31) Proteobacteria-Campylobacterales, (32) Proteobacteria-Gammaproteobacteria-other, (33) Proteobacteria- Alteromonadales, (34) Proteobacteria-Pseudomonadales, (35) ProteobacteriaThiotrichales, (36) Spirochaetes-LK-44f-uncultured bacterium, (37) Spirochaetes-MSBL2-uncultured bacterium, (38) Spirochaetes-PBS-18-other, (39) Spirochaetes-Spirochaetaceae, (40) TenericutesAcholeplasmatales.

The number of reads per incubated slurry for archaeal sequences varied from 9120 to 136,909 (Table S3). In all libraries from slurry samples, the highest average percentage of 16S rRNA reads for Archaea clustered within the families Methanomicrobiaceae (60.8\%), Methanosarcinaceae (16.3\%), and Methanosaetaeceae (9.3\%) (Figure S4). The fractional abundance of the two aceticlastic methanogenic families Methanosaetaceae and Methanosarcinaceae did not correlate to each other or other taxonomic groups and environmental parameters (Figure 5A and Figure S5). Both families did not correlate with the hydrogenotrophic methanogenic family Methanomicrobiaceae, among which Methanosarcinaceae showed significant negative correlation $(p<0.05)$. The relative abundance of Methanosaetaceae increased with increasing temperature, but was negatively affected by the presence of sulfate. Methanosarcinaceae did not show any significant positive correlation to any of the environmental parameters (Figure 5A and Figure S5). Unclassified Methanomicrobiales and EJ-E01 were positively correlated to methane, whereas Methanomicrobiaceae was positively correlated only to acetate (Figure S5). This result is consistent with the fact that Methanomicrobiaceae had high relative abundance in the slurries in which acetate accumulated to very high concentrations (Figure 5B). Methanogenium belonging to the family Methanomicrobiaceae was the most dominant genus among the slurries, followed by the genus Methanosarcina from the family Methanosarcinaceae (Figure 5A). Methanosaetaeceae was dominant only in two slurry samples incubated at $25{ }^{\circ} \mathrm{C}$ with low and without sulfate, with $43 \%$ and $67 \%$ of the reads, respectively. These reads belonged to Methanosaeta and unclassified Methanosaetaceae (Figure 5A).

The intact polar lipid (IPLs) distribution was used as a chemotaxonomic marker. IPL distributions varied substantially over time and differed between the various slurry incubations (Figure S6). Canonical correspondence analysis clustered the observed bacterial OTUs and IPLs into three groups (Figure S8; with abbreviations explained for the IPL groups). These groups are as follows: (1) phosphatidylethanolamine (PE), phosphatidic acid (PA), ornithine (OL), phosphatidylglycerol (PG), and phosphatidylinositol (PI) clustered more closely with Flavobacteriaceae (BBF), Cytophagaceae (BBC1), Bacteriodetes-SB-5 (BBS5), Marinilabiaceae (BBM), Actinobacteria-OPB41 (BAO), Bacteroidetes-BD2-2 (BBB), Bacteroidetes-VC2.1_Bac22 (BBV), and high-sulfate conditions; (2) monohexose (MH) and glucuronic acid (GlcA) clustered more closely with Anaerolineaceae (BCA2), Candidate division OP9 (BCO), Other Bacteria (BO), and low-sulfate conditions; (3) phosphatidylcholine (PC), lyso-phosphatidylcholine (LPC), dihexose (DH), trimethylornithine (TMO), Betaine, and dimethylphosphatidylethanolamine (DMPE) clustered more closely with Bacteroidetes-SB-1 (BBS), Bacteroidetes-WCHB1-69 (BBW), Bacteroidetes-vadinHA1 (BBVH), Chloroflexi-GIF9 (BCG), and low-sulfate conditions. 


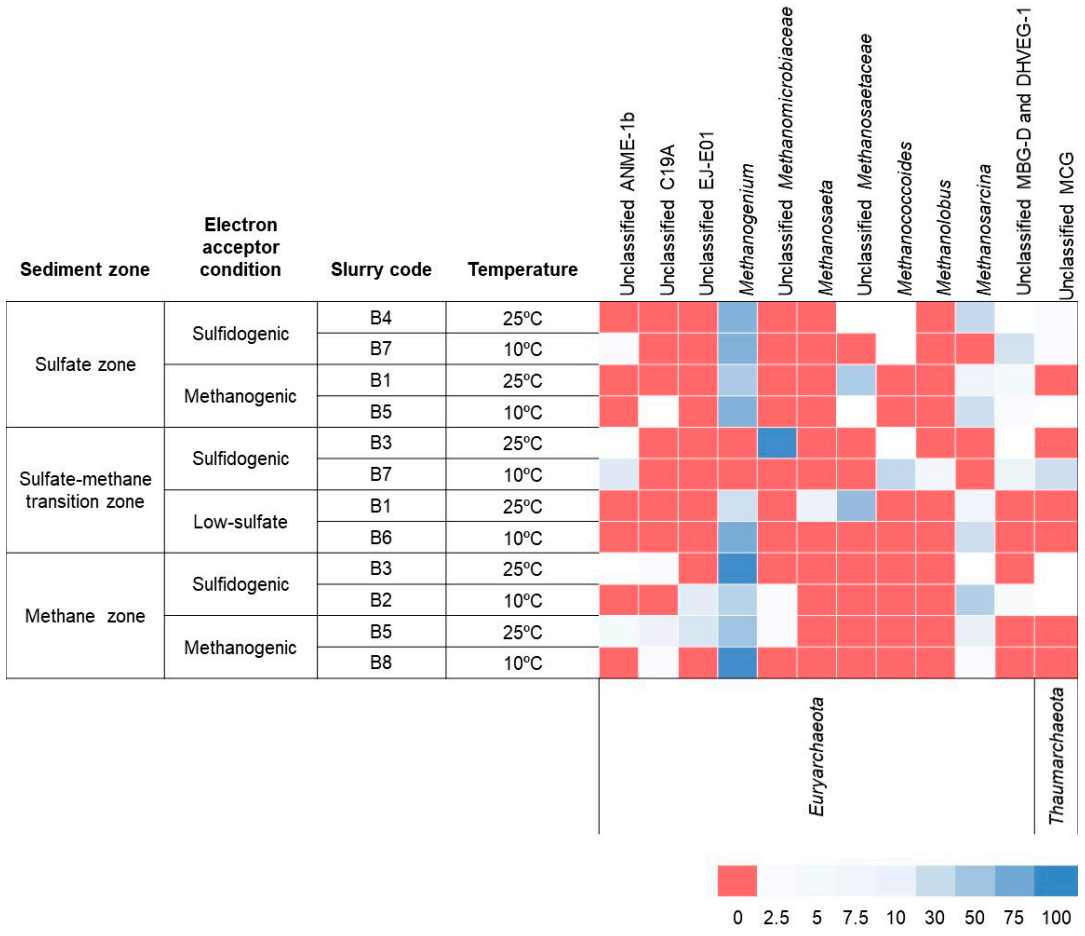

A

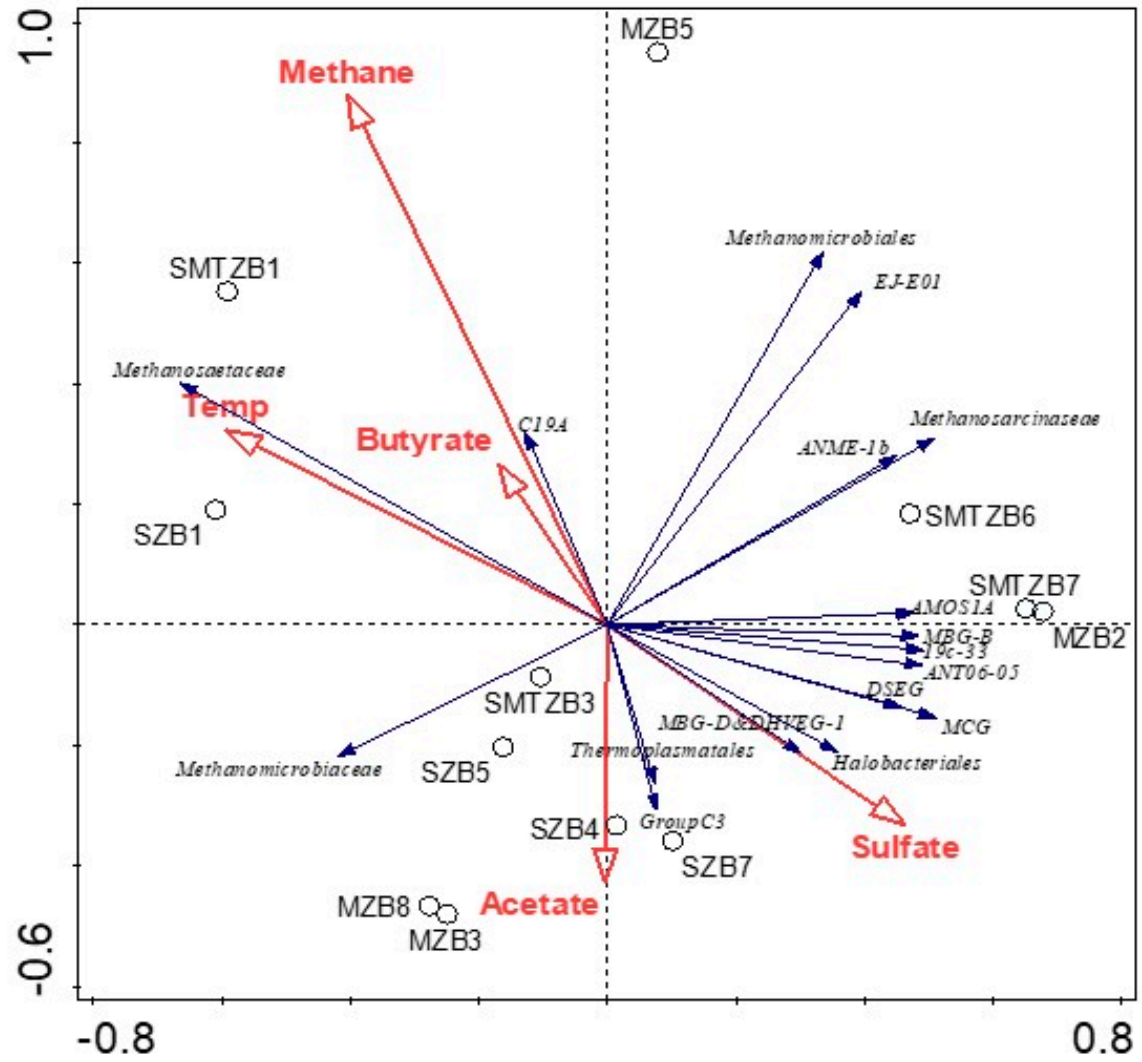

B

Figure 5. (A) The heatmap depicts the relative abundance of the most common ( $>5 \%$ ) archaeal $16 \mathrm{~S}$ rRNA gene sequences (unless unclassified) across the 12 slurries analyzed. The heatmap colors represent 
the relative percentage of the archaeal assignments within each sample. Colors shifted towards bright blue indicate higher abundance. (B) Redundancy Analysis Triplot showing relationship between Archaeal community composition at family level and environmental parameters. Environmental variables are given as red vectors. Blue vectors represent archaeal families. Families were included with a relative abundance of at least $1 \%$ in any sample. Vector length gives the variance that can be explained by a particular environmental parameter. Perpendicular distance reflects association, with smaller distances indicating a larger association. Temp: Temperature.

\section{Discussion}

\subsection{Butyrate Conversion in Aarhus Bay Sediment}

Our study shows that butyrate conversion in Aarhus Bay sediments is coupled to both sulfate reduction and methane production. The rapid consumption of sulfate in the slurries suggests that sulfate reduction is the dominant pathway of butyrate conversion in Aarhus Bay sediment. This is most likely due to the fact that sulfate reduction is energetically more favorable than methanogenesis [37]. The accumulation of acetate in all slurries indicated incomplete butyrate conversion (Figures 1-3). The decrease in acetate concentration coinciding with methane production suggested the occurrence of methanogenesis in the sulfate zone of Aarhus Bay (Figure 1A,C). This agrees with recent reports of the occurrence of methanogenesis in sulfate-rich marine sediments of Aarhus Bay [20].

The butyrate conversion trend in sulfate-free $\mathrm{SZ}$ and $\mathrm{MZ}$ slurries incubated at $25^{\circ} \mathrm{C}$ was similar in terms of early methane production and complete acetate consumption (Figures $1 \mathrm{C}$ and $3 \mathrm{C}$ ). Apparently, syntrophic conversion of butyrate under sulfate-free conditions is possible both in the sulfate and methane zones of Aarhus Bay sediments (Table S1, reactions 1, 5, 6 and 7).

\subsection{The Effect of Sulfate Concentration on Butyrate Conversion Dynamics}

Significant differences in terms of product formation and consumption in high $(20 \mathrm{mM})$ and low $\left(3 \mathrm{mM}\right.$ ) sulfate-amended SMTZ slurries at $25^{\circ} \mathrm{C}$ suggest that the sulfate concentration is an important environmental factor in butyrate conversion (Figure 2A,C). Reduced and delayed methane formation in high sulfate-amended slurries possibly indicated sulfide inhibition on methanogenesis [38]. Rapid methane formation after day 523 in high-sulfate-containing slurries might be related to the adaptation capacity of hydrogenotrophic methanogens to the slurry conditions, involvement in syntrophic butyrate conversion, and simultaneous increase of acetate (Figure 2A). This suggests that methanogenesis could still occur despite the ongoing sulfate reduction and the high sulfide level. On the other hand, high methane production with concomitant acetate consumption in low sulfate-amended SMTZ slurries indicated an efficient syntrophic butyrate conversion involving acetate- and hydrogen-dependent sulfate reduction and methanogenesis processes along the incubation (Figure 2C). Apparently, low amounts of sulfate stimulated the whole microbiome, resulting in a fast and dedicated population performing both sulfate reduction and methanogenesis.

\subsection{Bacterial and Archaeal Community Structure in the Enrichment Slurries}

In sulfate-amended slurries, the members of Desulfobacteraceae, Desulfovibrionaceae, Desulfobulbaceae, Syntrophomonadaceae, and Clostridiales are associated with butyrate conversion. The Desulfobacterium, Desulfonema, Desulfosarcina, Desulfoarculus genera belonging to Desulfobacteraceae couple complete butyrate oxidation to sulfate reduction [39]. The increase in the relative abundance of these genera in sediment slurries from both SZ and MZ suggested the existence of sulfate reducers in the sulfate, sulfate-methane transition, and methane zones of the sediment. In [40], the authors reported a high absolute abundance of Desulfobacteraceae in surface as well as subsurface sediments of Aarhus Bay. The relative abundance of Syntrophomonas increased in sulfate-free sediment slurries from the sulfate zone and sulfate-amended sediment slurries from the methane zone. This result showed 
that the presence of sulfate can decelerate the abundance of Syntrophomonas species, but did not inhibit the butyrate conversion by Syntrophomonas. Sulfate-reducing bacteria that directly couple butyrate oxidation to sulfate reduction generally grow faster than syntrophic butyrate degraders [18,41]. However, the growth rates of some syntrophic butyrate degraders were reported to be higher than those of some butyrate-oxidizing sulfate reducers [41]. One reason may be that they have similar kinetic properties [42] which allows syntrophic butyrate degraders to occur in sulfate-reducing ecosystems such as marine sediments and aquifers [14,18].

Anaerolineaceae became dominant at higher temperatures $\left(25^{\circ} \mathrm{C}\right)$ due to their ability to decompose dead biomass [43] and convert acetate in marine sediment slurries [44]. Considering that the slurries in our study were incubated for a very long period of time, the Anaerolineaceae might have scavenged organic compounds from decaying cells [45]. Since Anaerolineaceae contain all genes of the acetyl-CoA pathway [46], their involvement in acetate degradation cannot be excluded.

The most abundant IPLs identified in most of the sediment slurries are phosphatidylethanolamine (PE), which are often found in aquatic environments and sediments, and are produced by various groups of microorganisms, such as the sulfate reducers Desulfosarcina variabilis and Desulforhabdus amnigenus [47], and the bacterial members of ANME-1 [48].

The high abundance of SRB at the end of the slurry incubations and the positive correlation between PE IPLs and high-sulfate condition (Figure S8) might indicate that the occurrence of PE can be linked to the presence of SRB in enrichment slurries. The presence of trimethylornithine (TMO) IPLs in three butyrate-amended slurries from the methane zone (Figure S7, Table S4) was surprising since these lipids were originally identified in planctomycete isolates from ombrotrophic northern wetlands [49], and later observed in northern wetland peat [50], meso-oligotrophic lakes of Minnesota and Iowa [51], and Yellow Stone National Park hot spring microbial communities [52]. No planctomycete phylotypes were detected in any of the butyrate-amended methane zone-derived slurries, indicating that the observed TMOs were produced by other microbial groups or the relative abundance of planctomycete phylotypes was very low.

Methanogenium, belonging to Methanomicrobiaceae, dominated all slurry incubations, regardless from which zone the sediment originated and independent of the incubation temperature, except for one slurry (SMTZB7) (Figure 5A). Therefore, Methanogenium spp., which are specialized in $\mathrm{H}_{2}$ and formate utilization [53], and also known as psychrotrophs, are likely responsible for the consumption of $\mathrm{H}_{2} /$ formate produced as a result of incomplete conversion of butyrate and may act as syntrophic partners.

The dominance of hydrogenotrophic methanogens in near-surface marine sediments has previously been reported $[14,20,54]$. The absence of methane in sulfate-rich marine sediments might be due to methane oxidation coupled to methane production, leading to methane cycling in marine surface sediment [20]. The Methanosaetaceae dominate only the low-sulfate SMTZ and sulfate-free SZ slurries at $25^{\circ} \mathrm{C}$ (Figure 5A). This may be due to the low acetate levels towards the end of the incubation period and the high acetate affinity of Methanosaetaceae [55]. Another reason can be the competition with acetate-degrading Desulfobacteraceae, which were highly abundant in the original SMTZ (Figure S2). Acetate is mainly consumed by sulfate reducers in marine sediments, and some acetate-degrading sulfate reducers have slightly better growth kinetics than Methanosaeta [56]. Similar observations were reported by [57] who speculated that low sulfate may allow Methanosaetaceae to compete with sulfate reducers for acetate.

\section{Conclusions}

This study demonstrates that methanogenic archaea and sulfate-reducing bacteria are present and active in sediments of the sulfate zone, the sulfate-methane transition zone, and methane zone of Aarhus Bay and that there is no vertical separation of both groups in the sediment profile. Butyrate conversion could occur under both sulfate-reducing and methanogenic conditions regardless of the incubation temperature and the sediment depth (Figure 6). Conversion of butyrate by syntrophic communities 
throughout the sediment column suggests that continuous supply of available carbon might stimulate syntrophic butyrate degraders in the sulfate zone. Additionally, SRBs in sulfate-depleted sediment can contribute to the butyrate conversion even in the presence of low sulfate. We suggest that both groups of microbes survive in the sediment and butyrate conversion can proceed via sulfate reduction and methanogenesis simultaneously, though only in conditions of low sulfate. The results indicate that $\mathrm{H}_{2}$ and $\mathrm{CO}_{2}$ may be major substrates for methanogens, and the members of hydrogenotrophic methanogenic family Methanomicrobiaceae were the dominant archaea in the slurries. However, there is only limited competition between SRB and methanogens for acetate. The outcome of this study provides conclusive evidence that marine prokaryotes are metabolically flexible at limiting electron donor and acceptor conditions and the phylogenetic groups that are likely to thrive at different sediment depths.

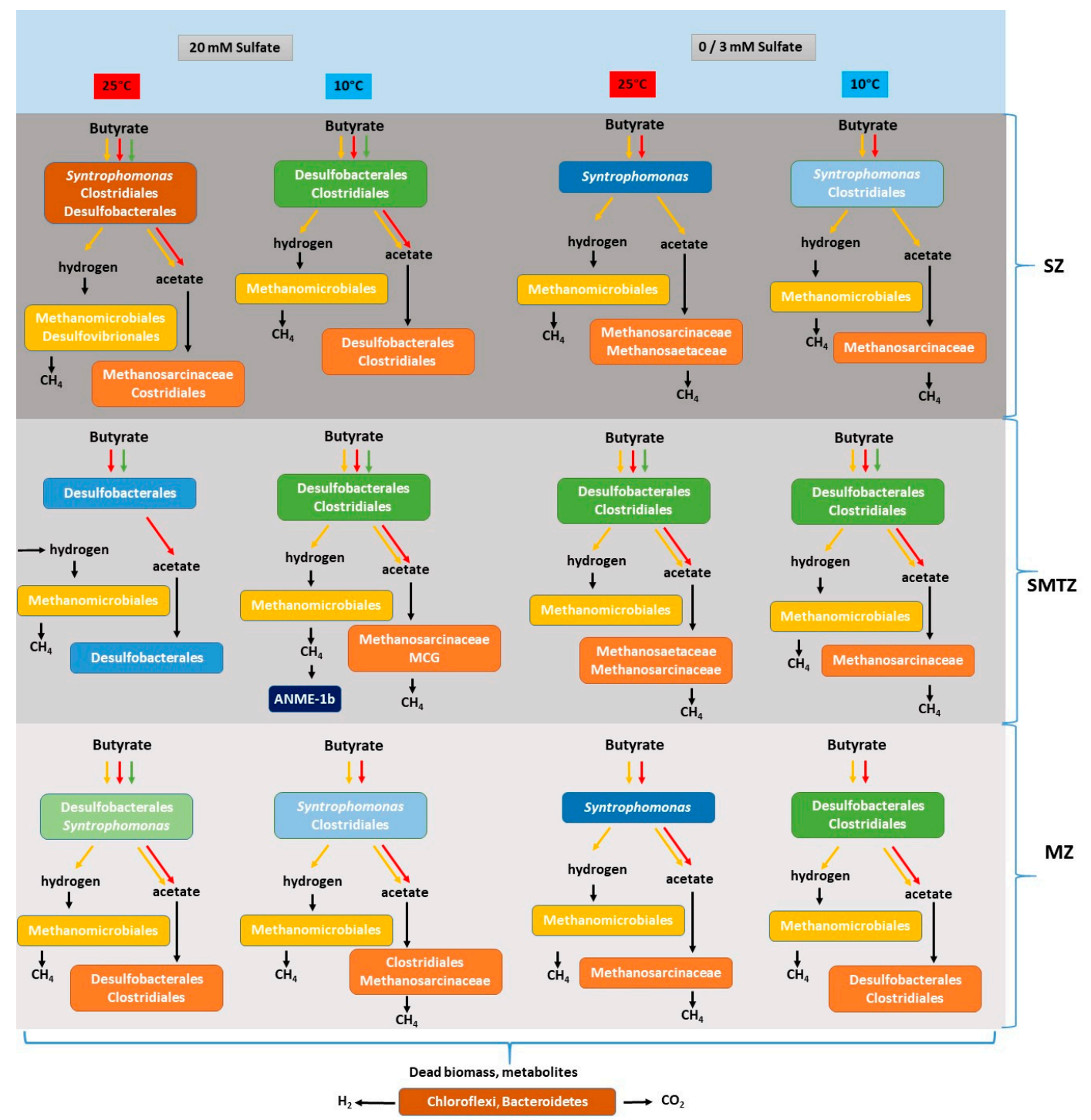

Figure 6. Overview of butyrate conversion and the proposed responsible microbial community at different temperatures and sulfate concentrations in enrichment slurries of sulfate, sulfate-methane transition, and methane zone sediment of Aarhus Bay. Possible butyrate conversion pathways are shown with different colored arrows; red arrows represent incomplete butyrate conversion coupled to sulfate reduction, green arrows represent complete butyrate conversion coupled to sulfate reduction, yellow arrows represent syntrophic butyrate conversion. Horizontal arrow represents the substrates originated from fermentation, decomposition of dead biomass, and/or metabolites. 
Supplementary Materials: The following are available online at http://www.mdpi.com/2076-2607/8/4/606/s1, Table S1: Overview of reactions examined in this study, Table S2: Overview of all the enrichment slurries fed with butyrate and the total amounts of the reactants consumed and products formed during the enrichment period, Table S3: The number of reads per sample generated by Pyrosequencing for Bacteria and HiSeq Illumina sequencing for Archaea, Table S4: Relative abundance (HPLC/MS mass chromatogram area, summed by IPL head group per gram sediment dry weight) of all IPLs identified in Aarhus Bay sediment and the enrichment slurries inoculated with this sediment, Figure S1: Depth profiles of sediment pore water sulfate, sulfide, and methane for Station M1, in Aarhus Bay, Denmark, Figure S2: Relative abundance of the bacteria in all slurries and environmental samples at family level, Figure S3: Heatmap representing the correlation between bacterial orders present at a relative abundance $>1 \%$ of total reads across the 12 slurry samples analyzed and experimental parameters, Figure S4: Relative abundance of the Archaea in all slurries and environmental samples at family level, Figure S5: Heatmap showing the correlation between archaeal families present at a relative abundance $>1 \%$ of total reads across the 12 slurry samples analyzed and experimental parameters, Figure S6: Percent relative abundance of IPLs in all enrichment slurries and environmental samples used for molecular analysis, Figure S7: Percent relative abundance of IPLs in all methane zone enrichment slurries, Figure S8: Canonical correspondence analysis of intact polar lipid (IPL) distribution, bacterial taxa distribution, and growth conditions for all enrichment slurries.

Author Contributions: D.O. and C.M.P. designed the research; D.O. conducted the experiments; E.K.M. and E.C.H. performed lipid analysis; E.K.M., E.C.H., and J.S.S.D. performed lipid analysis data interpretation; D.O. and C.M.P. analyzed all other data; D.O. drafted the manuscript with input of all authors. All authors have read and agreed to the published version of the manuscript.

Funding: This work was supported by the Wimek Graduate School of Wageningen University \& Research and the Darwin Center for Biogeosciences (the Netherlands). Research of Alfons J.M. Stams is supported by the SIAM Gravitation grant (project 024.002.002) of the Netherlands Ministry of Education, Culture and Science and the Netherlands Science Foundation (NWO) and an advanced grant of the European Research Council under the European Union's Seventh Framework Programme (FP/2007e2013)/ERC Grant Agreement (323009). This project also received funding from the European Research Council (ERC) under the European Union's Horizon 2020 research and innovation program (grant agreement no. 694569, MICROLIPIDS).

Acknowledgments: We gratefully acknowledge Mark A. Lever (Eidgenössische Technische Hochschule, Zurich, Switzerland), Kasper U. Kjeldsen, Hans Røy (Aarhus University, Aarhus, Denmark) for skillful technical assistance and the captains and crews of sailing vessel Marieje and research vessel Tyra for their help during different cruises. We thank dr. Peer Timmers, dr. Martin Liebensteiner and Kivanc Ozuolmez for assistance during sampling, Antonie van Gelder for technical assistance and Bart Nijsse and Daan van Vliet for bioinformatics support.

Conflicts of Interest: The authors declare no conflict of interest.

Sequence Data Deposition: The demultiplexed reads of the 16S rRNA gene amplicon sequences were deposited at the European Nucleotide Archive (ENA) under study PRJEB36640 (Bacteria) and PRJEB36882 (Archaea).

\section{References}

1. Jørgensen, B.B. Bacteria and Marine Biogeochemistry; Springer Science and Business Media LLC: Berlin/Heidelberg, Germany, 2006; Volume 2, pp. 169-206.

2. Canfield, D.; Kristensen, E.; Thamdrup, B. Heterotrophic Carbon Metabolism; Elsevier BV: Amsterdam, The Netherlands, 2005; Volume 48, pp. 129-166.

3. Mitterer, R.M. Methanogenesis and sulfate reduction in marine sediments: A new model. Earth Planet. Sci. Lett. 2010, 295, 358-366. [CrossRef]

4. Glombitza, C.; Egger, M.; Røy, H.; Jørgensen, B.B. Controls on volatile fatty acid concentrations in marine sediments (Baltic Sea). Geochim. Cosmochim. Acta 2019, 258, 226-241. [CrossRef]

5. Jørgensen, B.B.; Findlay, A.J.; Pellerin, A. The biogeochemical sulfur cycle of marine sediments. Front. Microbiol. 2019, 10, 849. [CrossRef] [PubMed]

6. Schink, B.; Stams, A.J.M. Syntrophism among Prokaryotes. In The Prokaryotes; Springer Science and Business Media LLC: Berlin/Heidelberg, Germany, 2013; pp. 471-493.

7. Widdel, F. Microbiology and ecology of sulfate- and sulfur-reducing bacteria. In Biology of Anaerobic Microorganisms; Zehnder, A.J.B., Ed.; John Wiley and Sons Inc.: New York, NY, USA, 1988; pp. 469-585.

8. Maltby, J.; Sommer, S.; Dale, A.W.; Treude, T. Microbial methanogenesis in the sulfate-reducing zone of surface sediments traversing the Peruvian margin. Biogeosciences 2016, 13, 283-299. [CrossRef]

9. Sela-Adler, M.; Ronen, Z.; Herut, B.; Antler, G.; Vigderovich, H.; Eckert, W.; Sivan, O. Co-existence of methanogenesis and sulfate reduction with common substrates in sulfate-rich estuarine sediments. Front. Microbiol. 2017, 8, 171. [CrossRef] 
10. Oremland, R.S.; Polcin, S. Methanogenesis and sulfate reduction: Competitive and noncompetitive substrates in estuarine sediments. Appl. Environ. Microbiol. 1982, 44, 1270-1276. [CrossRef]

11. Finke, N.; Hoehler, T.M.; Jørgensen, B.B. Hydrogen "leakage" during methanogenesis from methanol and methylamine: Implications for anaerobic carbon degradation pathways in aquatic sediments. Environ. Microbiol. 2007, 9, 1060-1071. [CrossRef]

12. Leloup, J.; Loy, A.; Knab, N.J.; Borowski, C.; Wagner, M.; Jørgensen, B.B. Diversity and abundance of sulfate-reducing microorganisms in the sulfate and methane zones of a marine sediment, Black Sea. Environ. Microbiol. 2007, 9, 131-142. [CrossRef]

13. Leloup, J.; Fossing, H.; Kohls, K.; Holmkvist, L.; Borowski, C.; Jørgensen, B.B. Sulfate-reducing bacteria in marine sediment (Aarhus Bay, Denmark): Abundance and diversity related to geochemical zonation. Environ. Microbiol. 2009, 11, 1278-1291. [CrossRef]

14. Kendall, M.M.; Liu, Y.; Boone, D.R. Butyrate- and propionate-degrading syntrophs from permanently cold marine sediments in Skan Bay, Alaska, and description of Algorimarina butyrica gen. nov., sp. nov. FEMS Microbiol. Lett. 2006, 262, 107-114. [CrossRef]

15. Kleikemper, J.; Schroth, M.; Sigler, W.V.; Schmucki, M.; Bernasconi, S.; Zeyer, J. Activity and diversity of sulfate-reducing bacteria in a petroleum hydrocarbon-contaminated aquifer. Appl. Environ. Microbiol. 2002, 68, 1516-1523. [CrossRef] [PubMed]

16. Dar, S.A.; Kuenen, J.G.; Muyzer, G. Nested PCR-denaturing gradient gel electrophoresis approach to determine the diversity of sulfate-reducing bacteria in complex microbial communities. Appl. Environ. Microbiol. 2005, 71, 2325-2330. [CrossRef] [PubMed]

17. Winderl, C.; Anneser, B.; Griebler, C.; Meckenstock, R.U.; Lueders, T. Depth-resolved quantification of anaerobic toluene degraders and aquifer microbial community patterns in distinct redox zones of a tar oil contaminant plume. Appl. Environ. Microbiol. 2007, 74, 792-801. [CrossRef] [PubMed]

18. Struchtemeyer, C.G.; Duncan, K.E.; McInerney, M.J. Evidence for syntrophic butyrate metabolism under sulfate-reducing conditions in a hydrocarbon-contaminated aquifer. FEMS Microbiol. Ecol. 2011, 76, $289-300$. [CrossRef] [PubMed]

19. Plugge, C.M.; Zhang, W.; Scholten, J.C.M.; Stams, A.J.M. Metabolic flexibility of sulfate-reducing bacteria. Front. Microbiol. 2011, 2, 81. [CrossRef]

20. Xiao, K.-Q.; Beulig, F.; Kjeldsen, K.U.; Jørgensen, B.B.; Risgaard-Petersen, N. Concurrent methane production and oxidation in surface sediment from Aarhus Bay, Denmark. Front. Microbiol. 2017, 8, 1198. [CrossRef]

21. Cline, J.D. Spectrophotometric determination of hydrogen sulfide in natural waters. Limnol. Oceanogr. 1969, 14, 454-458. [CrossRef]

22. Dale, A.; Aguilera, D.R.; Regnier, P.; Fossing, H.; Knab, N.J.; Jørgensen, B.B. Seasonal dynamics of the depth and rate of anaerobic oxidation of methane in Aarhus Bay (Denmark) sediments. J. Mar. Res. 2008, 66, 127-155. [CrossRef]

23. Van Gelder, A.H.; Aydin, R.; Alves, M.M.; Stams, A.J.M. 1,3-Propanediol production from glycerol by a newly isolated Trichococcus strain. Microb. Biotechnol. 2012, 5, 573-578. [CrossRef]

24. Ozuolmez, D.; Stams, A.J.M.; Plugge, C.M. Propionate converting anaerobic microbial communities enriched from distinct biogeochemical zones of Aarhus Bay, Denmark under sulfidogenic and methanogenic conditions. Microorganisms 2020, 8, 394. [CrossRef]

25. Timmers, P.H.A.; Widjaja-Greefkes, H.C.A.; Ramiro-Garcia, J.; Plugge, C.M.; Stams, A.J.M. Growth and activity of ANME clades with different sulfate and sulfide concentrations in the presence of methane. Front. Microbiol. 2015, 6, 869. [CrossRef] [PubMed]

26. Berry, D.; Ben Mahfoudh, K.; Wagner, M.; Loy, A. Barcoded primers used in multiplex amplicon pyrosequencing bias amplification. Appl. Environ. Microbiol. 2011, 77, 7846-7849. [CrossRef] [PubMed]

27. Azman, S.; Khadem, A.F.; Plugge, C.M.; Stams, A.J.M.; Bec, S.; Zeeman, G. Effect of humic acid on anaerobic digestion of cellulose and xylan in completely stirred tank reactors: Inhibitory effect, mitigation of the inhibition and the dynamics of the microbial communities. Appl. Microbiol. Biotechnol. 2016, 101, 889-901. [CrossRef] [PubMed]

28. Poncheewin, W.; Hermes, G.D.A.; Van Dam, J.C.J.; Koehorst, J.J.; Smidt, H.; Schaap, P.J. NG-Tax 2.0: A semantic framework for high-throughput amplicon analysis. Front. Genet. 2020, 10, 1366. [CrossRef] [PubMed] 
29. Quast, C.; Pruesse, E.; Yilmaz, P.; Gerken, J.; Schweer, T.; Yarza, P.; Peplies, J.; Glöckner, F.O. The SILVA ribosomal RNA gene database project: Improved data processing and web-based tools. Nucleic Acids Res. 2012, 41, D590-D596. [CrossRef]

30. Caporaso, J.G.; Kuczynski, J.; Stombaugh, J.; Bittinger, K.; Bushman, F.D.; Costello, E.K.; Fierer, N.; Peña, A.G.; Goodrich, J.K.; Gordon, J.I.; et al. QIIME allows analysis of high-throughput community sequencing data. Nat. Methods 2010, 7, 335. [CrossRef]

31. Bligh, E.G.; Dyer, W.J. A rapid method of total lipid extraction and purification. Can. J. Biochem. Physiol. 1959, 37, 911-917. [CrossRef]

32. Rütters, H.; Sass, H.; Cypionka, H.; Rullkötter, J. Phospholipid analysis as a tool to study complex microbial communities in marine sediments. J. Microbiol. Methods 2002, 48, 149-160. [CrossRef]

33. Pitcher, A.; Hopmans, E.C.; Schouten, S.; Damsté, J.S.S. Separation of core and intact polar archaeal tetraether lipids using silica columns: Insights into living and fossil biomass contributions. Org. Geochem. 2009, 40, 12-19. [CrossRef]

34. Sturt, H.F.; Summons, R.E.; Smith, K.; Elvert, M.; Hinrichs, K.-U. Intact polar membrane lipids in prokaryotes and sediments deciphered by high-performance liquid chromatography/electrospray ionization multistage mass spectrometry—new biomarkers for biogeochemistry and microbial ecology. Rapid Commun. Mass Spectrom. 2004, 18, 617-628. [CrossRef]

35. Moore, E.K.; Hopmans, E.C.; Rijpstra, W.I.C.; Villanueva, L.; Damsté, J.S.S. Elucidation and identification of amino acid containing membrane lipids using liquid chromatography/high-resolution mass spectrometry. Rapid Commun. Mass Spectrom. 2016, 30, 739-750. [CrossRef] [PubMed]

36. McGarigal, K.; Stafford, S.; Cushman, S. Multivariate Statistics for Wildlife and Ecology Research; Springer Science and Business Media LLC: Berlin/Heidelberg, Germany, 2000.

37. Muyzer, G.; Stams, A.J.M. The ecology and biotechnology of sulphate-reducing bacteria. Nat. Rev. Genet. 2008, 6, 441-454. [CrossRef] [PubMed]

38. Pender, S.; Toomey, M.; Carton, M.; Eardly, D.; Patching, J.W.; Colleran, E.; O'Flaherty, V. Long-term effects of operating temperature and sulphate addition on the methanogenic community structure of anaerobic hybrid reactors. Water Res. 2004, 38, 619-630. [CrossRef] [PubMed]

39. Kuever, J. The Family Desulfobacteraceae; Springer Science and Business Media LLC: Berlin/Heidelberg, Germany, 2014; pp. 45-73.

40. Jochum, L.M.; Chen, X.; Lever, M.A.; Loy, A.; Jørgensen, B.B.; Schramm, A.; Kjeldsen, K.U. Depth distribution and assembly of sulfate-reducing microbial communities in marine sediments of Aarhus Bay. Appl. Environ. Microbiol. 2017, 83, e01547-17. [CrossRef] [PubMed]

41. Oude Elferink, S.J.W.H.; Visser, A.; Hulshoff Pol, L.W.; Stams, A.J.M. Sulfate reduction in methanogenic bioreactors. FEMS Microbiol. Rev. 1994, 15, 119-136.

42. McInerney, M.J.; Beaty, P.S. Anaerobic community structure from a nonequilibrium thermodynamic perspective. Can. J. Microbiol. 1988, 34, 487-493. [CrossRef]

43. Kleinsteuber, S.; Schleinitz, K.M.; Vogt, C. Key players and team play: Anaerobic microbial communities in hydrocarbon-contaminated aquifers. Appl. Microbiol. Biotechnol. 2012, 94, 851-873. [CrossRef]

44. Webster, G.; Sass, H.; Cragg, B.A.; Gorra, R.; Knab, N.J.; Green, C.J.; Mathes, F.; Fry, J.C.; Weightman, A.; Parkes, R.J. Enrichment and cultivation of prokaryotes associated with the sulphate-methane transition zone of diffusion-controlled sediments of Aarhus Bay, Denmark, under heterotrophic conditions. FEMS Microbiol. Ecol. 2011, 77, 248-263. [CrossRef]

45. Yamada, T.; Sekiguchi, Y. Cultivation of uncultured chloroflexi subphyla: Significance and ecophysiology of formerly uncultured chloroflexi 'subphylum i' with natural and biotechnological relevance. Microbes Environ. 2009, 24, 205-216. [CrossRef]

46. Hug, L.A.; Castelle, C.; Wrighton, K.; Thomas, B.C.; Sharon, I.; Frischkorn, K.R.; Williams, K.H.; Tringe, S.G.; Banfield, J.F. Community genomic analyses constrain the distribution of metabolic traits across the Chloroflexi phylum and indicate roles in sediment carbon cycling. Microbiome 2013, 1, 22. [CrossRef]

47. Rütters, H.; Sass, H.; Cypionka, H.; Rullkötter, J. Monoalkylether phospholipids in the sulfate-reducing bacteria Desulfosarcina variabilis and Desulforhabdus amnigenus. Arch. Microbiol. 2001, 176, 435-442. [CrossRef] [PubMed]

48. Rossel, P.; Lipp, J.S.; Fredricks, H.F.; Arnds, J.; Boetius, A.; Elvert, M.; Hinrichs, K.-U. Intact polar lipids of anaerobic methanotrophic archaea and associated bacteria. Org. Geochem. 2008, 39, 992-999. [CrossRef] 
49. Moore, E.K.; Hopmans, E.C.; Rijpstra, W.I.C.; Villanueva, L.; Dedysh, S.; Kulichevskaya, I.S.; Wienk, H.; Schoutsen, F.; Damsté, J.S.S. Novel mono-, di-, and trimethylornithine membrane lipids in northern wetland planctomycetes. Appl. Environ. Microbiol. 2013, 79, 6874-6884. [CrossRef] [PubMed]

50. Moore, E.K.; Villanueva, L.; Hopmans, E.C.; Rijpstra, W.I.C.; Mets, A.; Dedysh, S.; Damsté, J.S.S. Abundant trimethylornithine lipids and specific gene sequences are indicative of planctomycete importance at the oxic/anoxic interface in sphagnum-dominated northern wetlands. Appl. Environ. Microbiol. 2015, 81, 6333-6344. [CrossRef]

51. Bale, N.J.; Hopmans, E.C.; Schoon, P.L.; De Kluijver, A.; Downing, J.A.; Middelburg, J.J.; Damsté, J.S.S.; Schouten, S. Impact of trophic state on the distribution of intact polar lipids in surface waters of lakes. Limnol. Oceanogr. 2016, 61, 1065-1077. [CrossRef]

52. Boyer, G.M.; Schubotz, F.; Summons, R.E.; Woods, J.; Shock, E.L. Carbon oxidation state in microbial polar lipids suggests adaptation to hot spring temperature and redox gradients. Front. Microbiol. 2020, 11, 229. [CrossRef]

53. Garcia, J.-L.; Ollivier, B.; Whitman, W.B. The Order Methanomicrobiales; Springer Science and Business Media LLC: Berlin/Heidelberg, Germany, 2006; pp. 208-230.

54. Parkes, R.; Cragg, B.; Roussel, E.; Webster, G.; Weightman, A.; Sass, H. A review of prokaryotic populations and processes in sub-seafloor sediments, including biosphere:geosphere interactions. Mar. Geol. 2014, 352, 409-425. [CrossRef]

55. Jetten, M.S.M.; Zehnder, A.J.B.; Stams, A.J.M. Methanogenesis from acetate: A comparison of the acetate metabolism in Methanothrix soehngenii and Methanosarcina spp. FEMS Microbiol. Lett. 1992, 88, 181-198. [CrossRef]

56. Stams, A.J.M.; Plugge, C.M.; De Bok, F.A.M.; Van Houten, B.H.G.W.; Lens, P.N.L.; Dijkman, H.; Weijma, J. Metabolic interactions in methanogenic and sulfate-reducing bioreactors. Water Sci. Technol. 2005, 52, 13-20. [CrossRef]

57. Struchtemeyer, C.G.; Elshahed, M.S.; Duncan, K.E.; McInerney, M.J. Evidence for aceticlastic methanogenesis in the presence of sulfate in a gas condensate-contaminated aquifer. Appl. Environ. Microbiol. 2005, 71, 5348-5353. [CrossRef] 